\title{
Improving Detection Chlorine by Field Effect Gas Sensor with Using Temperature Pulse Mode.
}

\author{
Nikolay N. Samotaev ${ }^{1}$, Arthur V. Litvinov ${ }^{1}$, Maia O. Etrekova ${ }^{1}$ \\ ${ }^{1}$ National Research Nuclear University MEPHI, 115409, Kasirskoe highway 31, Moscow, Russian \\ nnsamotaev@mephi.ru
}

\begin{abstract}
The gas analytical system for chlorine gas measurement based on metal-insulator-semiconductor field effect (MIS FE) type sensor has been developed. High sensitivity of MIS FE sensor to chlorine allows measuring concentrations in the sub-ppb level and to be stable for overload hydrogen gas concentration typically present in industrial electrolysis application. With the pulse heating mode, the response and relaxation times of the MIS sensor are reduced by an order of magnitude which gives chance to use one for high precision environmental control.
\end{abstract}

Key words: Field effect sensor, gas sensor, Chlorine.

\section{Introduction}

The Chlorine gas concentration measurement in air is a very specific problem because hazardous concentration for human health is very low (for residential area is around $20 \mathrm{ppb}$ and $670 \mathrm{ppb}$ for working zone by Russian standard of environmental protection). Sub-ppb level is not achieving by liquid electrochemical sensors and also there are several important applications where these sensors nonapplicable from a short operation life time and extremely working condition such as humidity extremes (very dry or too much humid atmosphere), temperature drop or operation under permanently high concentration of $\mathrm{Cl}_{2}$. Therefore, the purpose of the present work was creation inexpensive and useful sensor system for low $\mathrm{Cl}_{2}$ concentration measurement in presence of $\mathrm{H}_{2}$ based on stable and solid state MIS FE sensors.

The MIS FE sensors (capacity and transistor types) have a high sensitivity to the concentrations of various gases. The sensitivity of MIS FE sensor of the Pd-SiO2-Si type to $\mathrm{H}_{2}$ was first demonstrated in [1]. Later was found sensitivity of MIS FE sensors to non-content hydrogen gases in [2].

\section{Experiment}

To detect necessary sub-ppb ranges $\mathrm{Cl}_{2}$ concentrations we have used MIS-FE sensor with structure $\mathrm{Pd}-\mathrm{Ta}_{2} \mathrm{O}_{5}-\mathrm{SiO}_{2}-\mathrm{Si}$. Thin film palladium gate of MIS-FE sensor was obtained by pulse laser deposition [3].

Under primary tests the using sensor gives opposite amplitude responses to $\mathrm{H}_{2}$ and $\mathrm{Cl}_{2}$ mean that molecules of these gases interact with different types of traps at the metalinsulator interface: $\mathrm{H}_{2}$ molecules with negatively charged traps and $\mathrm{Cl}_{2}$ molecules with traps charged positively.

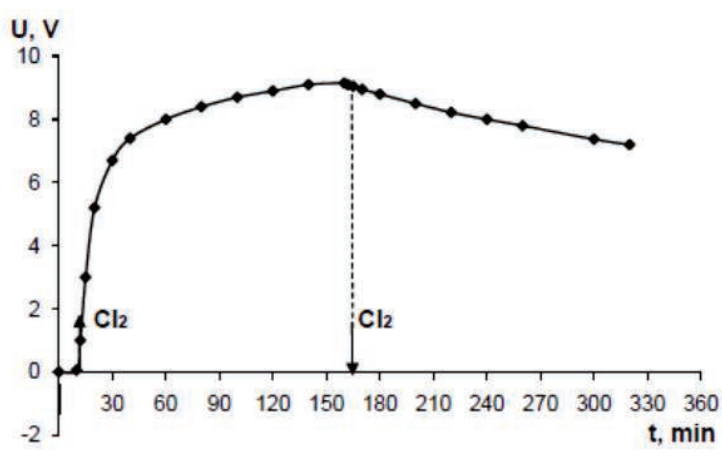

Fig. 1. The response of the MIS-FE sensor to 50 ppb of chlorine at $100{ }^{\circ} \mathrm{C}$ constant working temperature. Signal are given after electronic converter.

As can be seen from Fig. 1, MIS-FE sensors have long response $\left(\tau_{0,9}=70 \mathrm{~min}\right)$ and relaxation times $\left(\tau_{0,1} \rightarrow \infty\right)$ at $100{ }^{0} \mathrm{C}$ the operating temperature. For comparison, at the same temperature, response and relaxation times of the MIS-FE sensor to hydrogen at a concentration of several $50 \mathrm{ppb}\left(\tau_{0,9}=\tau_{0,1}=10\right.$ $\min )$. 


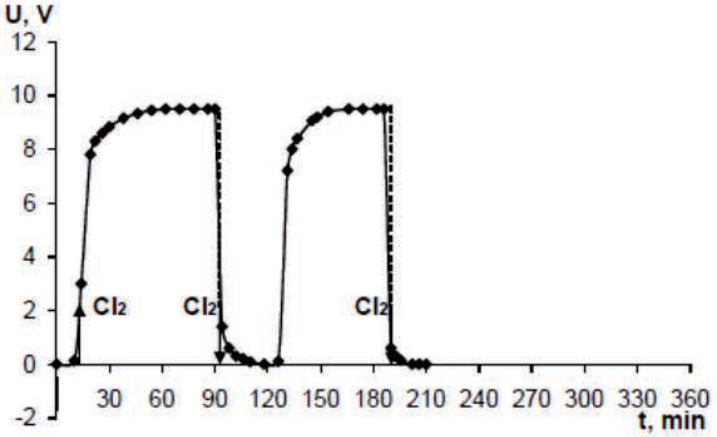

Fig. 2. The response of the MIS-FE sensor to 50 ppb of chlorine at pulse heating mode $190^{\circ} \mathrm{C} / 100^{\circ} \mathrm{C}$ working temperature. Signal is given after electronic converter.

The results of measurements of the sensitivity of MIS FE sensors to $\mathrm{Cl}_{2}$ in the pulsed heating mode are shown in Fig. 2. In this working mode, the sensitivity of the sensor is $200 \mathrm{~V} / \mathrm{ppm}$, the response time is $\tau_{0,9}=10 \mathrm{~min}$, the relaxation time is $\left(\tau_{0,1}=7 \mathrm{~min}\right.$. It is not yet clear why in the pulse heating mode the response time of the sensor is longer than the relaxation time, however, the values that parameters are already acceptable for the use as a sensitive element of the gas analyzer. We applied a pulse heating mode for creating a chlorine gas analyzer. The response of the MIS sensor in the gas analyzer has the schematic form shown in Fig. 3.

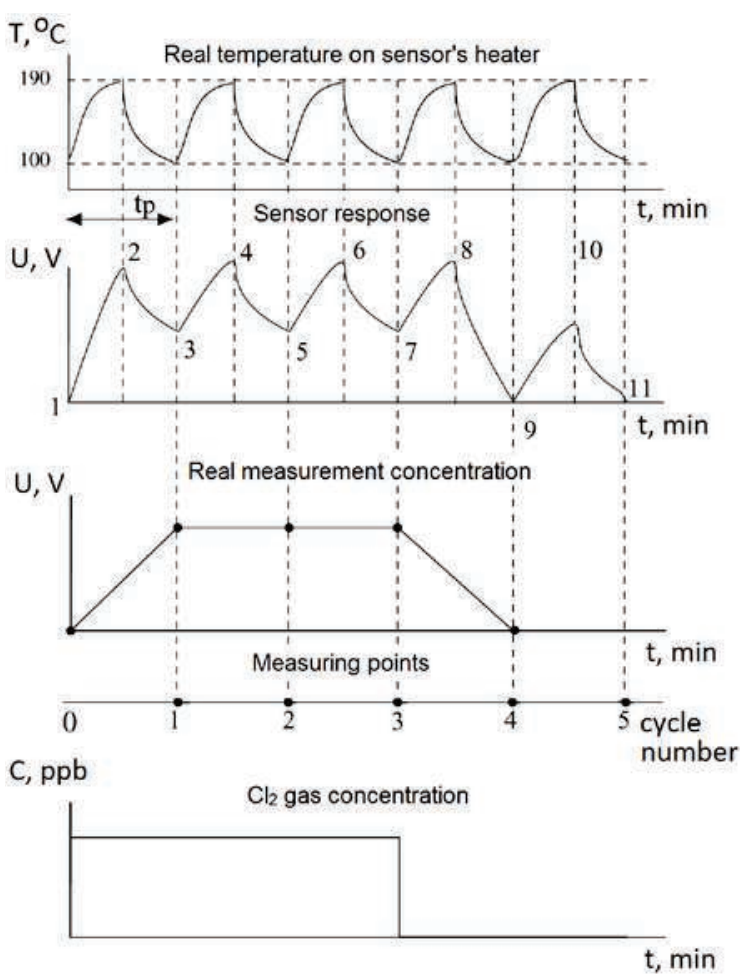

Fig. 3. The measuring principle of the $\mathrm{Cl}_{2}$ gas concentration by MIS-FE sensor operating in the pulse heating mode ( $t_{p}$ - time between two measurements of the $\mathrm{Cl}_{2}$ gas concentration).
The high sensitivity to $\mathrm{Cl}_{2}$ was obtained during measurements in laboratory conditions. The absolute error of such measurements is $10 \mathrm{mV}$, such error allows one to measure $\mathrm{Cl}_{2}$ concentrations at the level of $0.1 \mathrm{ppb}$. However, when we using a MIS FE sensor as a sensitive element in a gas analyzer under real (atmospheric) conditions measurement error may increases by an order of magnitude due to the influence of uncontrolled external factors.

Tests have shown that in real (atmospheric) conditions with a gas analyzer using MIS FE sensor starting to measure $\mathrm{Cl}_{2}$ concentrations from several $\mathrm{ppb}$. The selectivity of the gas analytical system can be improved by using a two-channel measuring system with $\mathrm{Cl}_{2}$ filtration as a present in the work [3] for sub-ppb $\mathrm{H}_{2} \mathrm{~S}$ gas concentration.

\section{Conclusion}

The significant magnitude of response the MIS sensor to $\mathrm{Cl}_{2}(1.8-2 \mathrm{nF} / \mathrm{ppm})$ makes one possible to use it as a sensitive element of chlorine gas analyzers with sensitivity at $\mathrm{ppb}$ level. Significantly speed-up of gas analyzer system response can done by pulse heating mode of the MIS-FE sensor. Simultaneous sensitivity to ppb-level concentrations of chlorine and hydrogen makes the MIS-FE sensors an excellent tool for environmental control in industrial electrochlorination process.

The developed gas analytical system based on MOF FE sensor has been successfully applied to control the environmental in the plant for extraction of platinum group metals from spent automotive catalysts by hydrometallurgy methods in presence of $\mathrm{HCl}$ electrolysis products.

\section{Acknowledgement}

This work was supported by the Ministry Education and Science Russian Federation (Grant No. 14.575.21.0153 from 26.09.2017, unique identifier RFMEFI57517X0153).

\section{References}

[1] I. Lundstrom, and et al. A hydrogen-sensitive Pdgate MOS transistor, Journal of Applied Physics 46 (9), 3876-3881 (1975); doi: 10.1063/1.322185

[2] I.N. Nikolaev, E.V. Emelin, Portable NO2 gas analyzer in the concentration range $0.02-2 \mathrm{ppm}$ based on a MDS-sensor, Measurement Techniques 47 (11), 1113-1115 (2004); doi: 10.1007/s11018-004-0016-6

[3] N. Samotaev, and et al. MIS - FE sensors for low concentration of $\mathrm{H} 2 \mathrm{~S}$ for environmental monitoring, Procedia Engineering 5, 1216-1219 (2010); doi: 10.1016/j.proeng.2010.09.331 